\title{
A Bibliometric Overview of the Field of Type-2 Fuzzy Sets and Systems
}

Amit K. Shukla, Dept. of Computer Science, South Asian University, New Delhi, India Sumit Kumar Bansal, Dept. of Computer Science, South Asian University, New Delhi, India Taniya Seth, Dept. of Computer Science, South Asian University, New Delhi, India Aparna Basu, Dept. of Computer Science, South Asian University, New Delhi, India Robert John, LUCID, School of Computer Science, University of Nottingham, Nottingham, U.K.

Pranab K. Muhuri, Dept. of Computer Science, South Asian University, New Delhi, India

\begin{abstract}
Fuzzy Sets and Systems is an area of computational intelligence, pioneered by Lotfi Zadeh over 50 years ago in a seminal paper in Information and Control. Fuzzy Sets (FSs) deal with uncertainty in our knowledge of a particular situation. Research and applications in FSs have grown steadily over 50 years. More recently, we have seen a growth in Type-2 Fuzzy Set (T2 FS) related papers, where T2 FSs are utilized to handle uncertainty in real-world problems. In this paper, we have used bibliometric methods to obtain a broad overview of the area of T2 FSs. This method analyzes information on the bibliographic details of published journal papers, which includes title, authors, author address, journals and citations, extracted from the Science and Social Science Citation Indices in the Web of Science (WoS) database for the last 20 years (1997-2017). We have compared the growth of publications in the field of FSs, and its subset T2 FSs, identified highly cited papers in T2 FSs, highly cited authors, key institutions, and main countries with researchers involved in T2 FS related research.
\end{abstract}

Online Resource: http://www.sau.int/ cilab/

Further statistics are made available as supplementary materials on the given link.

Corresponding Author: Pranab K. Muhuri (Email: pranabmuhuri@cs.sau.ac.in)

This paper has been accepted for publication in the February 2020 issue of the IEEE Computational Intelligence Magazine as a Discussion Forum Article. 


\section{INTRODUCTION}

Data in the real world is gathered from many sources. Considering that none of the processes in the real world is 'ideal', the data collected generally possess some kind of uncertainty, and information about some features or characteristics of the data are either incorrect or incomplete. Uncertainty is, therefore, a major challenge in real world applications, and there was a need felt, to have a theoretical framework within the discipline of Mathematics and Computer Science for handling such unknown, incomplete or uncertain information ${ }^{3}$. A solution was provided by Zadeh [1] in 1965 when he proposed the fuzzy set theory to bridge the gap between certain and uncertain environments. Although Zadeh's work did not attract much attention initially, from the mid-70's a number of scientists began examining this area. Several professional associations were started, and the first conference was held in USA in 1982. European and Asian researchers had also started to show increased attention to the field since the mid-70's. In 1985, the International Fuzzy Systems Association (IFSA) was created which held its first conference in Palma de Mallorca, in Spain. Today, fuzzy set theory has emerged as a powerful way of quantitatively representing and manipulating the imprecision in a variety of problems, both theoretical and applied. It is now an established field with thousands of researchers studying different theoretical or practical aspects, as can be verified by bibliometrics.

Bibliometrics (equivalently scientometrics) refers to a technique of statistical analysis of scientific papers, using only bibliographic details or meta-data on papers, as is available from citation indexes such as Web of Science (WoS) or Scopus. It enables extraction of many features in the scientific field to which the papers belong, without actually reading the entire corpus. To extract the papers in a field, a suitable keyword or string is used to query the WoS database. Care needs to be taken at this stage to ensure that the query retrieves all relevant

${ }^{3}$ There is also another form of uncertainty, called randomness, for which a theoretical framework is provided by probability theory. 
information, and ensures that both precision and recall are high. The data has information on papers, including title, author names, journal, publication year, author address and citations. This can be analyzed to obtain a measure of the productivity and citation of authors, institutions or countries. From the citation data, one can obtain highly cited papers, or authors, journals, institutions and countries that publish the most cited articles. Time trends can also be obtained. Bibliometric analysis has been performed in different disciplines.

The first bibliometric analysis and mapping of Fuzzy Sets (FSs) research were done by Herrera and co-authors in 2009 for Spain, a country that held a leading position in fuzzy research at the time [2]. In 2011, the same Spanish group analyzed the entire field covering research in fuzzy set theory in all countries [3]. An overview of the origin of FSs, journals used, prominent authors, and research can be found in a later study by Merigo, Gil-Lafuente and Yager in 2015 [4]. Van Eck and Waltman [5-6] have mapped the related field of Computational Intelligence in 2006 and again in 2007. Recently, Bustince has also studied the history of various types of FSs in [77]. Other Computer Science fields have also been covered, e.g. big data [7], linguistic decision making [8], Atanassov intuitionistic fuzzy sets [9], Industry 4.0 [29], fuzzy decision making [10], etc. Apart from subject wise bibliometric analysis, there are also journal specific studies in the literature, e.g. [11-13], [48-52].

Type-1 (T1) FSs are limited by the certainty of their membership function (MF) values, something that was already recognized by Zadeh [24] when he introduced type-2 (T2) FSs, whose MF values are no longer certain but are modeled as intervals that can be uniformly or non-uniformly weighted. A T2 FS is characterized by its footprint of uncertainty (FOU), bounded by two type-1 MFs, called lower MF (LMF) and upper MF (UMF). Although T2 FSs were first introduced by Zadeh in 1975, it was Karnik and Mendel [22] who first introduced T2 fuzzy logic systems (FLS) in 1998. For a history of why it took so long for this to happen, see [79]. 
T2 FSs have been used extensively by many researchers in a broad range of applications in which MF uncertainties are modeled by their FOUs as a way to handle application uncertainties completely within the framework of FSs (e.g., [14]-[16], [18]-[25], [43]-[46], [53]-[76]). To get a better overview of the overall research on all aspects of T2 FSs and systems, see [55] which lists more than 1,000 articles, and was recently made public by Mendel.

The trends in research publications indicate that the overall field of fuzzy sets and systems has grown from around 1,648 publications ${ }^{4}$ in 1997 to around 9,130 publications in 2017. During the same period, T2 publications have grown from almost none to more than 230 . Comparing the two growth rates during the past 10 years, it would seem that the T2 FS field has been growing faster than the overall FS field, which has motivated the present scientometric study.

Fig. 1 shows a comparison of the percentage growth ${ }^{5}$ in the T1 and T2 fuzzy fields. When we take a closer look at the two curves, we can conclude that the percentage growth for T2 fuzzy was very dynamic during the early years but is now approaching the percentage growth of the entire FS field, implying that the T2 field is no longer an emerging technology but has matured. Therefore, it is worth pointing out that the T2 field should no longer be referred to as an emerging field.

The main contributions of this study are given below:

1. It provides a detailed bibliometric analysis of all the publications on T2 FSs and systems as indexed in WoS core collections Science Citation Index-Expanded (SCIE), Social Sciences Citation Index (SSCI) and Emerging Sources Citation Index (ESCI) database.

\footnotetext{
${ }^{4}$ These counts are annual, and $\mathrm{T} 2$ publications are not included in these counts.

${ }^{5}$ The percentage growth is calculated as: Percentage growth $=\frac{A-B}{B} \times 100 \%$, where $A=$ Publications (current year) and $B=$ Publications (previous year).
} 
2. It is the first such work that has analyzed the key contributing authors on T2 FS related research and their institutions.

3. It also provides the topmost venues (journals) which are chosen by the key contributors to publish their research work on T2 FSs and systems.

4. It discusses the top 20 most highly cited articles on T2 FSs.

5. It also analyzes various aspects of the contributions from different countries.

6. It provides the co-authorship analysis of T2 FSs related research.

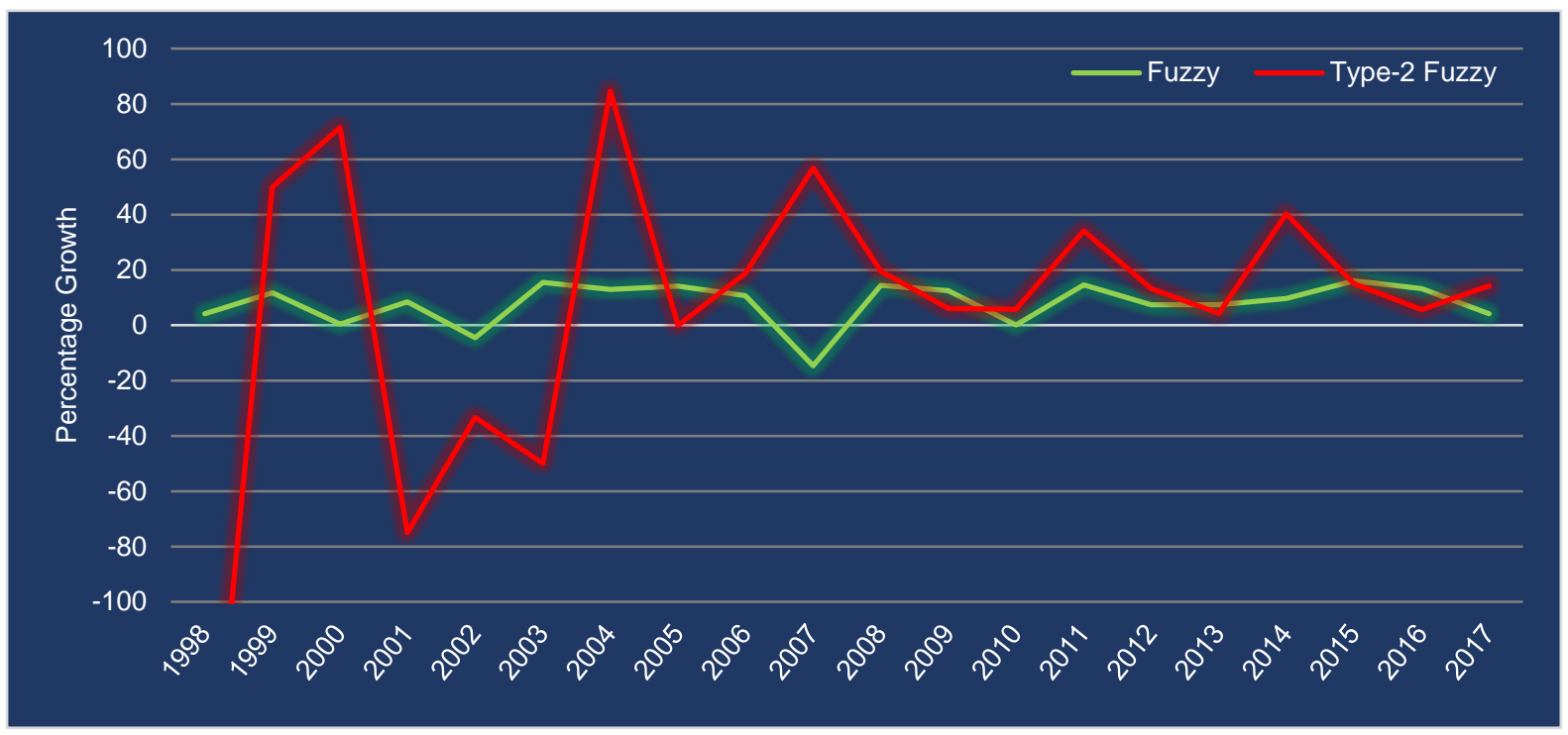

Fig 1. Publications growth curves for research in FSs and T2 FSs and systems.

This paper is organized as follows: Section II discusses data collection and methodology; Section III provides scientometric analysis and quantitative results on research growth, discipline, top source journals, most productive and highly cited authors, and highly cited papers; Section IV covers a country-wise analysis along with analysis of institutional performances. Finally, Section V concludes this paper with discussions on findings of the study and its future scopes.

II. DATA COLlection AND Methodology 
Bibliographic details of research outputs (articles, reviews, proceedings papers, etc.) were collected from the WoS index using the query term ${ }^{6}$ “Type-2 Fuzzy” till December 31, 2017. All the papers in which this term is present in any of the three key locations: Title, Abstract, and Keywords are extracted. The query term "Type-2 Fuzzy" was chosen since it covers 'Type-2 Fuzzy Sets' as well as its two common variants: 'General Type-2 Fuzzy Sets (GT2 FSs)' and 'Interval Type-2 Fuzzy Sets (IT2 FSs) ${ }^{7}$. Databases included in our search were the SCI-E, SSCI and ESCI. The data corresponds to the duration of 20 years from 1997 to 2017.

A total of 1,288 papers were retrieved with a total of 35,072 citations. Each of the records consisted of 66 Fields, such as Author(s), Affiliations(s), Title, Abstract, Citations, Source, etc. for each paper. Cited references were also collected for these publications. The data was pre-processed manually to eliminate duplicate/outliers so that only unique records remained in the extracted data. Then, the data was processed programmatically in R. In all calculations, we used integer counting ${ }^{8}$; i.e., when there was a co-authored paper, each author was credited with one paper. This was also done for institutions and countries.

\section{ANALYSIS AND RESULTS}

The following scientometric analysis and results are given in the subsequent subsections: (A) Qualitative Analysis, (B) Discipline wise Analysis, (C) Top Source Journals, (D) Most Productive and Highly Cited Authors, (E) Most Cited Papers, and (F) Keywords Visualization using VOSviewer [80].

\footnotetext{
${ }^{6}$ For traditional FSs we have used the keyword "Fuzzy" for the search in the WoS.

${ }^{7}$ IT2 FSs are closely related to (some even say they are generalization of) Interval-valued fuzzy sets (IVFSs) [78]. If the papers on IVFSs have used the keyword "type-2 fuzzy" in any of these key locations (Title, Abstract, and Keywords), then they are automatically included. Papers that didn't use the keyword "type-2 fuzzy", in any of the three key locations were excluded.

${ }^{8}$ It is possible to do "fractional counting" where an author is credited an equal fraction, depending on the number of authors. Both methods are in use and it is not clear which one is much better than the other.
} 


\section{A. Qualitative Analysis}

A qualitative and visual analysis of the data usually precedes detailed analysis. After noting the growth pattern of the T2 fuzzy research area, we note the level of citations. We found that 1,157 papers out of 1,288 papers were cited, constituting $89.82 \%$ of the total. This is indicative of an active field. There are 131 un-cited papers, but they also include recent papers, from the past one year or two. Among the cited papers, most of the papers were cited only 0-50 times (993 papers or $77.1 \%$ ) while only 7 papers had more than 500 citations.

\section{B. Discipline wise Analysis}

As expected, Computer Science as a broad category, contains the maximum number of papers in the domain of T2 FSs with 905 papers, followed by Engineering, (503 papers, 39.05\%), and Automation Control Systems (167 papers, 12.97\%). Mathematics papers cover only $9.16 \%$ of the field with 118 papers.

There are in fact 149 distinct subject categories in the data indicating that the applications are widely dispersed across different areas. The papers may be assigned to more than a single category indicating interdisciplinary work.

\section{Top Source Journals}

In the case of top contributing journals in the field, parameters taken into account are the Total Publication (TP) count, Total Citation (TC) count, and Cites/Paper. One more parameter, $h$-index is also computed for visualizing the impact of these sources; it is the number of publications $(N)$ that have attained more than $N$ citations for the number of cited papers.

The journals with the most T2 papers are IEEE Transactions on Fuzzy Systems and Information Sciences (TP > 100 papers) and Applied Soft Computing (TP > 50 papers). IEEE Transactions on Fuzzy Systems is also the most cited journal with total citations being 10,737 
in 20 years, or about 537 citations per year on average. It is cited almost twice as frequently as the next most frequently cited journal in the field, Information Sciences $(\mathrm{TC}=5,864)$. Other journals with more than 1,000 citations in 20 years are Expert Systems with Applications $(\mathrm{TC}=1,872)$ and Applied Soft Computing $(\mathrm{TC}=1,664)$, Fuzzy Sets and Systems $(\mathrm{TC}=1,290)$ and IEEE Computational Intelligence Magazine $(\mathrm{TC}=1,060)$. Table 1 provides the top 15 journals with the highest number of publications.

If we look at the size-independent indicator, citations per paper (Cites/Paper), another set of journals emerges which have high citations but with relatively few papers. Physica A with a single paper has 113 citations. IEEE Transactions on Systems, Man and Cybernetics with 93.5 cites per paper, was followed by IEEE Transactions on Fuzzy Systems with 74.56 cites per paper. Note that most journals which published T2 papers are not core fuzzy journals. The only core journal for fuzzy papers is IEEE Transactions on Fuzzy Systems. This highlights the fact that not only theory but also applications of FSs have also been highly cited even when they are published in small numbers and are dispersed in journals outside the field of FSs.

TABle 1: ToP 15 Journals With Highest Publications of T2 FS RESEARCH

\begin{tabular}{|c|c|c|c|c|}
\hline JOURNAL TITLE & TP & TC & CITES/ PAPER & $h$-INDEX \\
\hline IEEE TRANSACTIONS ON FUZZY SYSTEMS & 144 & 10,737 & 74.56 & 49 \\
\hline INFORMATION SCIENCES & 107 & 5,864 & 54.80 & 41 \\
\hline APPLIED SOFT COMPUTING & 72 & 1,664 & 23.11 & 22 \\
\hline EXPERT SYSTEMS WITH APPLICATIONS & 53 & 1,872 & 35.32 & 23 \\
\hline JOURNAL OF INTELLIGENT \& FUZZY SYSTEMS & 52 & 166 & 3.19 & 7 \\
\hline SOFT COMPUTING & 44 & 552 & 12.55 & 13 \\
\hline FUZZY SETS AND SYSTEMS & 35 & 1,290 & 36.86 & 19 \\
\hline INTERNATIONAL JOURNAL OF FUZZY SYSTEMS & 31 & 206 & 6.65 & 7 \\
\hline NEUROCOMPUTING & 31 & 242 & 7.81 & 10 \\
\hline ENGINEERING APPLICATIONS OF ARTIFICIAL INTELLIGENCE & 24 & 520 & 21.67 & 12 \\
\hline $\begin{array}{l}\text { INTERNATIONAL JOURNAL OF UNCERTAINTY FUZZINESS AND } \\
\text { KNOWLEDGE-BASED SYSTEMS }\end{array}$ & 22 & 222 & 10.09 & 7 \\
\hline IEEE COMPUTATIONAL INTELLIGENCE MAGAZINE & 16 & 1,060 & 66.25 & 9 \\
\hline $\begin{array}{l}\text { INTERNATIONAL JOURNAL OF INNOVATIVE COMPUTING } \\
\text { INFORMATION AND CONTROL }\end{array}$ & 16 & 235 & 14.69 & 9 \\
\hline ISA TRANSACTIONS & 16 & 199 & 12.44 & 9 \\
\hline KNOWLEDGE-BASED SYSTEMS & 16 & 512 & 32.00 & 11 \\
\hline
\end{tabular}


If we use the $h$-Index as an indicator for T2 FS publications, the journals with the highest $h$ Index are seen to be IEEE Transactions on Fuzzy Systems $(h=49)$, Information Sciences (41), Expert Systems with Applications (23), Applied Soft Computing (22), and Fuzzy Sets and Systems (19).

\section{Most Productive and Highly Cited Authors}

Results for the most productive authors in research in T2 FSs are discussed in this section. As can be seen from Table 2, Mendel has the highest number of papers and citations in this field. Mendel has the highest total citations at 9,809, followed by Castillo with 3,005 citations, John with 2,839, Melin with 2,486 citations, Liang with 2,274 citations, and Karnik with 2,072 citations. Mendel has the highest $h$-Index at 44, followed by Castillo at 34 and Melin at 28. Karnik has the highest citations per paper (405.4) followed by Liang (252.67) and Liu (236.17).

\section{E. Highly Cited Papers}

This section lists the top 20 highly cited papers in T2 FSs, dates ranging from 1999-2012. The highest citation till now for a T2 FSs paper is by Mendel and John, written in 2002, titled 'Type 2 Fuzzy sets made simple' [17] which received 1,129 citations.

TABle 2: Top 15 Most Productive Authors.

\begin{tabular}{c|cccc}
\hline AUTHOR & TP & TC & CITES/ PAPER & h-INDEX \\
\hline MENDEL, JM & 69 & 9,809 & 142.16 & 44 \\
CASTILLO, O & 65 & 3,005 & 46.23 & 34 \\
MELIN, P & 52 & 2,486 & 47.81 & 28 \\
HAGRAS, H & 35 & 1,257 & 35.91 & 16 \\
PEDRYCZ, W & 23 & 514 & 22.35 & 11 \\
ZARANDI, MHF & 23 & 325 & 14.13 & 10 \\
WU, DR & 19 & 1,483 & 78.05 & 15 \\
JOHN, RI & 18 & 2,839 & 157.72 & 15 \\
TURKSEN, IB & 17 & 456 & 26.82 & 10 \\
KAYNAK, O & 16 & 474 & 29.63 & 11 \\
CHEN, TY & 16 & 413 & 25.81 & 11 \\
LIN, TC & 16 & 310 & 19.38 & 10 \\
\hline
\end{tabular}




\begin{tabular}{c|cccc}
\hline CHEN, SM & 15 & 681 & 45.40 & 11 \\
CASTRO, JR & 15 & 482 & 32.13 & 10 \\
LIU, XW & 15 & 422 & 28.13 & 9 \\
\hline
\end{tabular}

Usually, reviews are more cited, but this does not seem to be the case here. Of the 20 highly cited papers, as many as 11 are in IEEE Transactions on Fuzzy Systems, with an impact factor IF $=8.415$. Twelve (12) papers have been authored/co-authored by Mendel. This is the highest number of papers by any individual in this elite set. Nine (9) authors have a single paper only in this list. After Mendel, Karnik has 3 papers in this list. Liang and Hagras each have authored/co-authored 3 papers while John and Liu have 2 papers each.

Among the top 20 cited papers (see Table 3), the 2002 paper [17] from Mendel and John has the highest citations per year of 75.27. It is followed by the paper titled "Interval type- 2 fuzzy logic systems made simple" published in IEEE Transactions on Fuzzy Systems [19] of 2006 and had 827 citations over 10 years with 75.18 citations/year. It is authored by Mendel, John and Liu. The paper "Interval type-2 fuzzy logic systems: Theory and design", [27] in IEEE Transactions on Fuzzy Systems, by Liang and Mendel (2000), got 55.94 citations per year. The main authors in the top 10 cited papers are, Mendel (12), Karnik (3), Hagras (3), John (2), Liang (2), Liu (2). The numbers in the brackets denote the number of papers by the respective authors in the top 20 highly cited publications.

\section{F. Keywords Visualization using VOSviewer}

A visualization of research intensity of different areas within T2 FS for the entire period (1997-2017), using the visualization software VOSviewer [80], is shown in Fig. 2. Red areas indicate high research intensity as in a 'heat map'. Keywords 'type-2 fuzzy set/s', 'type-2 fuzzy logic', and 'interval type-2 fuzzy set' lie in the red areas. These are the most frequently used keywords/topics in the papers of type- 2 fuzzy research. The other relative hot spots are: 
'uncertainty', 'fuzzy control', and 'fuzzy sets'. The positions of the research areas are determined by the co-occurrence frequency of the keywords.

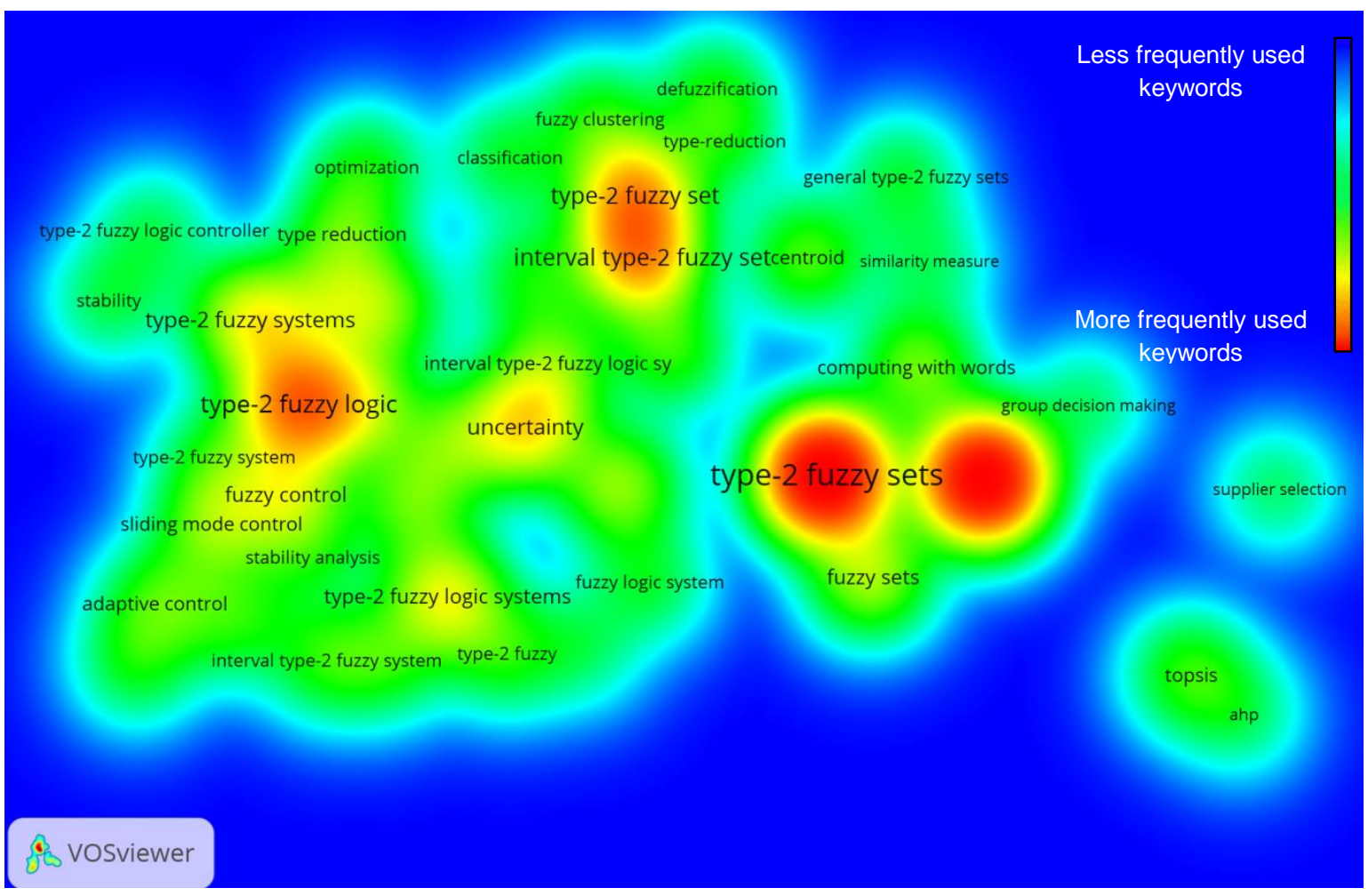

Fig. 2. Topic density visualization using VOSviewer.

\section{COUNTRY WiSE DISTRIBUTION}

Many countries have researchers working in the area of T2 FSs. Here we study various aspects of the contributions by researchers from different regions/countries. It includes country wise distribution, time dynamics, impact analysis, institution analysis, etc.

\section{Country Level-Analysis}

At present, researchers from 68 countries have published on T2 FSs. More than $50 \%$ of the publications have been contributed by the researchers of only 4 countries including: China, Iran, USA, and Taiwan. Out of these, Chinese researchers have produced the largest number of papers $(\mathrm{TP}=274)$. It is approximately a fifth of the total share of all papers in T2 FS (21.2\%). Iranian researchers stand at the second position with the share of $13.04 \%$, having published 168 papers. The other productive countries with researchers on T2 FSs, after 
China and Iran, are USA, Taiwan, United Kingdom, and Turkey with not much differentiated shares of $12.8 \%, 10.7 \%, 8.77 \%$, and $8.22 \%$ having $165,138,113$ and 106 publications, respectively. 
TABle 3: Top 20 Cited PAPERS IN T2 FSs.

\begin{tabular}{|c|c|c|c|c|c|}
\hline S.NO & AUTHORS & TITLE & CITES & AGE & CITES/AGE \\
\hline 1 & MENDEL, JM; JOHN, RI (2002) & TYPE-2 FUZZY SETS MADE SIMPLE, IEEE TRANSACTIONS FUZZY SYST. [17] & 1,129 & 15 & 75.27 \\
\hline 2 & LIANG, QL; MENDEL, JM (2000) & INTERVAL TYPE-2 FUZZY LOGIC SYSTEMS: THEORY AND DESIGN, IEEE TRANSACTIONS FUZZY SYST. [27] & 934 & 17 & 54.94 \\
\hline 3 & $\begin{array}{l}\text { MENDEL, JM; JOHN, RI; LIU, FL } \\
\text { (2006) }\end{array}$ & INTERVAL TYPE-2 FUZZY LOGIC SYSTEMS MADE SIMPLE, IEEE TRANSACTIONS FUZZY SYST. [19] & 827 & 11 & 75.18 \\
\hline 4 & $\begin{array}{l}\text { KARNIK, NN; MENDEL, JM; } \\
\text { LIANG, QL (1999) }\end{array}$ & TYPE-2 FUZZY LOGIC SYSTEMS, IEEE TRANSACTIONS FUZZY SYST. [28] & 768 & 18 & 42.67 \\
\hline 5 & $\begin{array}{l}\text { KARNIK, NN; MENDEL, JM } \\
\text { (2001) }\end{array}$ & CENTROID OF A TYPE-2 FUZZY SET, INFORMATION SCIENCES [30] & 601 & 16 & 37.56 \\
\hline 6 & HAGRAS, HA (2004) & $\begin{array}{l}\text { A HIERARCHICAL TYPE-2 FUZZY LOGIC CONTROL ARCHITECTURE FOR AUTONOMOUS MOBILE ROBOTS, IEEE } \\
\text { TRANSACTIONS FUZZY SYST. [31] }\end{array}$ & 555 & 13 & 42.69 \\
\hline 7 & MENDEL, JM (2007) & TYPE-2 FUZZY SETS AND SYSTEMS: AN OVERVIEW, IEEE COMPUTATIONAL INTELLIGENCE MAGAZINE [32] & 422 & 10 & 42.20 \\
\hline 8 & $\begin{array}{l}\text { KARNIK, NN; MENDEL, JM } \\
\text { (2001) }\end{array}$ & OPERATIONS ON TYPE-2 FUZZY SETS, FUZZY SETS AND SYSTEMS [33] & 354 & 16 & 22.13 \\
\hline 9 & MENDEL, JM (2007) & ADVANCES IN TYPE-2 FUZZY SETS AND SYSTEMS, INFORMATION SCIENCES [34] & 345 & 10 & 34.50 \\
\hline 10 & WU, HW; MENDEL, JM (2002) & $\begin{array}{c}\text { UNCERTAINTY BOUNDS AND THEIR USE IN THE DESIGN OF INTERVAL TYPE-2 FUZZY LOGIC SYSTEMS, IEEE } \\
\text { TRANSACTIONS FUZZY SYST. [35] }\end{array}$ & 272 & 15 & 18.13 \\
\hline 11 & HAGRAS, H (2007) & $\begin{array}{l}\text { TYPE-2 FLCS: A NEW GENERATION OF FUZZY CONTROLLERS, IEEE COMPUTATIONAL INTELLIGENCE } \\
\text { MAGAZINE [36] }\end{array}$ & 232 & 10 & 23.20 \\
\hline 12 & WU, DR; MENDEL, JM (2009) & ENHANCED KARNIK-MENDEL ALGORITHMS, IEEE TRANSACTIONS FUZZY SYST. [38] & 228 & 8 & 28.50 \\
\hline 13 & LIANG, QL; MENDEL, JM (2000) & $\begin{array}{l}\text { EQUALIZATION OF NONLINEAR TIME-VARYING CHANNELS USING TYPE-2 FUZZY ADAPTIVE FILTERS, IEEE } \\
\text { TRANSACTIONS FUZZY SYST. [37] }\end{array}$ & 218 & 17 & 12.82 \\
\hline 14 & HWANG, C; RHEE, FCH (2007) & $\begin{array}{l}\text { UNCERTAIN FUZZY CLUSTERING: INTERVAL TYPE-2 FUZZY APPROACH TO C-MEANS, IEEE TRANSACTIONS } \\
\text { FUZZY SYST. [39] }\end{array}$ & 208 & 10 & 20.80 \\
\hline 15 & CHEN, SM; LEE, LW (2010) & $\begin{array}{l}\text { FUZZY MULTIPLE ATTRIBUTES GROUP DECISION-MAKING BASED ON THE INTERVAL TYPE-2 TOPSIS METHOD, } \\
\text { EXPERT SYSTEMS WITH APPLICATIONS I42] }\end{array}$ & 201 & 7 & 28.71 \\
\hline 16 & $\begin{array}{l}\text { MARTINEZ, R; CASTILLO, O; } \\
\quad \text { AGUILAR, LT (2009) }\end{array}$ & $\begin{array}{l}\text { OPTIMIZATION OF INTERVAL TYPE-2 FUZZY LOGIC CONTROLLERS FOR A PERTURBED AUTONOMOUS } \\
\text { WHEELED MOBILE ROBOT USING GENETIC ALGORITHMS, INFORMATION SCIENCES [40] }\end{array}$ & 195 & 8 & 24.38 \\
\hline 17 & LIU, FL (2008) & $\begin{array}{l}\text { AN EFFICIENT CENTROID TYPE-REDUCTION STRATEGY FOR GENERAL TYPE-2 FUZZY LOGIC SYSTEM, } \\
\text { INFORMATION SCIENCES [26] }\end{array}$ & 192 & 9 & 21.33 \\
\hline 18 & CASTILLO, O; MELIN, P (2012) & $\begin{array}{l}\text { A REVIEW ON THE DESIGN AND OPTIMIZATION OF INTERVAL TYPE-2 FUZZY CONTROLLERS, APPLIED SOFT } \\
\text { COMPUTING I471 }\end{array}$ & 179 & 5 & 35.80 \\
\hline 19 & MENDEL, JM (2004) & $\begin{array}{l}\text { COMPUTING DERIVATIVES IN INTERVAL TYPE-2 FUZZY LOGIC SYSTEMS, IEEE TRANSACTIONS FUZZY SYST. } \\
{[41]}\end{array}$ & 178 & 13 & 13.69 \\
\hline 20 & $\begin{array}{l}\text { WAGNER, C; HAGRAS, H } \\
\text { (2010) }\end{array}$ & $\begin{array}{l}\text { TOWARD GENERAL TYPE-2 FUZZY LOGIC SYSTEMS BASED ON ZSLICES, IEEE TRANSACTIONS FUZZY SYST. } \\
{[57]}\end{array}$ & 177 & 7 & 25.29 \\
\hline
\end{tabular}




\section{Impact Analysis}

In this section, we analyze the quality of the publications (measured in terms of citations) by researchers from different countries, divided into four periods (1997-2001), (2002-2006), (2007-2011), (2012-2017). The countries are sorted on the basis of the metric TC. The top five countries in terms of citations are USA, UK, China, Taiwan, Mexico and Spain, in order.

If we look at the most recent period, countries with the highest citations are China, Mexico, Taiwan, UK, USA and Spain. Fig. 3 shows the country-level citations in the 4 periods (1997-2001), (2002-2006), (2007-2011), (2012-2017) for research on T2 FSs.

\section{Growth Rate}

T2 FSs originated in the USA and researchers in the country published the largest number of papers in the initial 15 years. The number of papers from the researchers in USA has declined in recent years while researchers in other countries like China and Taiwan have published more. In Fig. 4 we see the total production plotted against the average annual productivity growth in T2 FSs for researchers in different countries. Researchers in China have published the largest number of papers (>200) and also has a fairly high growth rate of 15.5\%. Researchers in Iran have shown a considerably higher growth rate of $13.4 \%$ in the last decade.

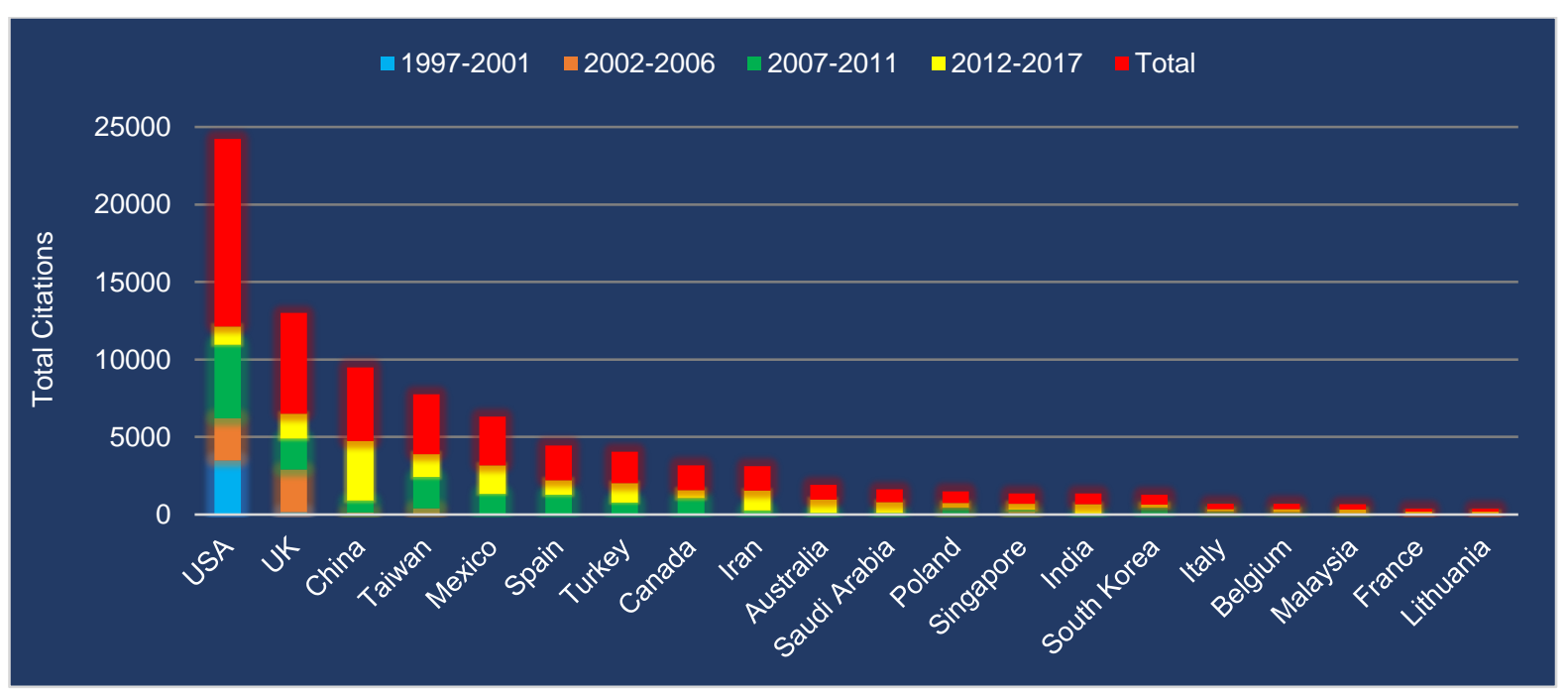


Fig. 3. Country Level Citations for research on T2 FSs (1997-2017).

However, researchers in USA and Taiwan have more than a hundred papers each but the growth rate has been low (5\% for Taiwanese researchers and $-22.3 \%$ for researchers in the USA). Publications by the researchers in UK also have a low growth rate of $-8.3 \%$. Works published by the researchers in Turkey, Mexico, and India have grown at the rate of 6.7, 1.7, and 6.5 percent, respectively. Papers by researchers in the USA, which has been at third position among all other countries, saw a decline of growth rate in recent years and is currently showing the lowest growth rate amongst the top 20 countries. This is mainly because of Prof. Mendel's retirement, since he was continuously contributing in earlier years.

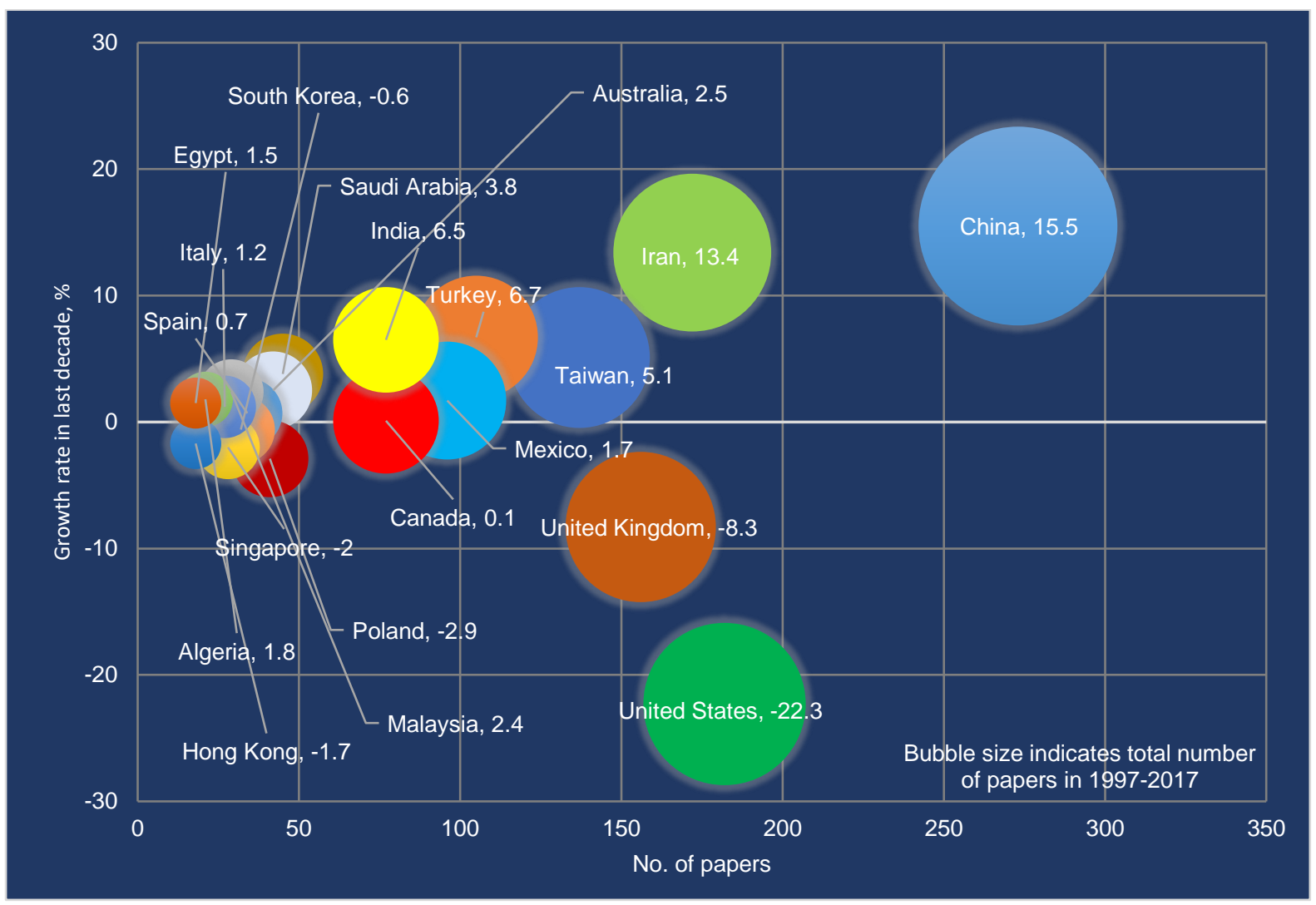

Fig. 4. Percentage growth of papers in T2 FSs by researchers in different countries in the last decade (2008-2017) as compared to starting years (1997-2007).

\section{Institutional Performance}


This section discusses the Top 20 Universities or Organizations in T2 FS research. As available in Table 4, the top institution is the University of Southern California, researchers from which contributed $5.7 \%$ to the published papers in T2 FSs. It is the only institution from the USA in the top 20 list. It also happens to have the highest number of citations $(10,104)$. The next most productive organization is the Tijuana University of Technology in Mexico with $5.05 \%$ share in the productivity and has the third highest citations with a count of 2,886 . At $3^{\text {rd }}$ and $4^{\text {th }}$ positions are Essex University (UK) and Amirkabir University (Iran) with $2.95 \%$ and $2.72 \%$ of papers, respectively. De Montfort University in UK and King Abdul Aziz University in Saudi Arabia are next at $5^{\text {th }}$ and $6^{\text {th }}$ positions with $2.56 \%$ and $2.33 \%$ share, respectively. Out of these, De Montfort University is observed to have accumulated the second highest citations $(3,465)$. Islamic Azad University, Iran is $7^{\text {th }}$ with $2.25 \%$ share and Istanbul Technical University in Turkey is 8 th with $2.10 \%$ share. Universidad Autonoma De Baja California, Mexico and National Chung Hsing University, Taiwan are at $9^{\text {th }}$ and $10^{\text {th }}$ spot.

Most Influential Authors from Top Institutions:

Mendel authored - or co-authored $-91.89 \%$ of the papers attributed to University of Southern California, USA. His citation counts are almost the same as that of his university.

TABle 4: Institutional Productivity, TP, Citations TC

\begin{tabular}{ccccc}
\hline S. NO. & ORGANIZATIONS & TP & TC & $\%$ \\
\hline 1 & UNIVERSITY OF SOUTHERN CALIFORNIA & 74 & 10,104 & 5.75 \\
2 & TIJUANA INST TECHNOLOGY & 65 & 2,886 & 5.05 \\
3 & UNIVERSITY OF ESSEX & 38 & 1,820 & 2.95 \\
4 & AMIRKABIR UNIVERSITY OF TECHNOLOGY & 35 & 393 & 2.72 \\
5 & DE MONTFORT UNIVERSITY & 33 & 3,465 & 2.56 \\
6 & KING ABDULAZIZ UNIVERSITY & 30 & 598 & 2.33 \\
7 & ISLAMIC AZAD UNIVERSITY & 29 & 240 & 2.25 \\
8 & ISTANBUL TECHNICAL UNIVERSITY & 27 & 475 & 2.10 \\
9 & UNIVERSIDAD AUTONOMA DE BAJA CALIFORNIA & 26 & 1,085 & 2.02 \\
10 & NATIONAL CHUNG HSING UNIVERSITY & 23 & 771 & 1.79 \\
11 & SOUTHEAST UNIVERSITY CHINA & 23 & 641 & 1.79 \\
12 & UNIVERSITY OF ALBERTA & 23 & 535 & 1.79
\end{tabular}




\begin{tabular}{lcccc}
13 & CHANG GUNG UNIVERSITY & 21 & 507 & 1.63 \\
14 & POLISH ACADEMY OF SCIENCES & 21 & 431 & 1.63 \\
15 & DEAKIN UNIVERSITY & 20 & 362 & 1.55 \\
16 & BOHAI UNIVERSITY & 18 & 821 & 1.40 \\
17 & INDIAN INSTITUTE OF TECHNOLOGY SYSTEM & 18 & 125 & 1.40 \\
18 & FENG CHIA UNIVERSITY & 17 & 423 & 1.32 \\
19 & NATIONAL TAIWAN UNIVERSITY OF SCIENCE TECHNOLOGY & 17 & 742 & 1.32 \\
20 & SHIRAZ UNIVERSITY OF TECHNOLOGY & 17 & 163 & 1.32 \\
\hline
\end{tabular}

Castillo from Tijuana Institute of Technology contributed $90.77 \%$ to publications and $96.26 \%$ to citations of that institute. After University of Southern California, the highest citations per paper $(\mathrm{ACPP}=105)$ were found for De Montfort University for which the main contributor was John. The next highest citations per paper were obtained by Essex University in the UK, where Hagras was the main contributor.

\section{Co-authorship Study}

It can be seen from Fig. 5 that the main actors have their own groups of co-authors as shown using different colors. Mendel, John, Hagras, Kumbasar, Bustince and Kaynak appear as the main characters in the interconnected clusters seen on the left. On the right is an independent cluster with few connections to the other cluster, with Castillo and Mendez as the main characters. The interconnection between the left and right nodes represents the connection between the authors of both sides. 


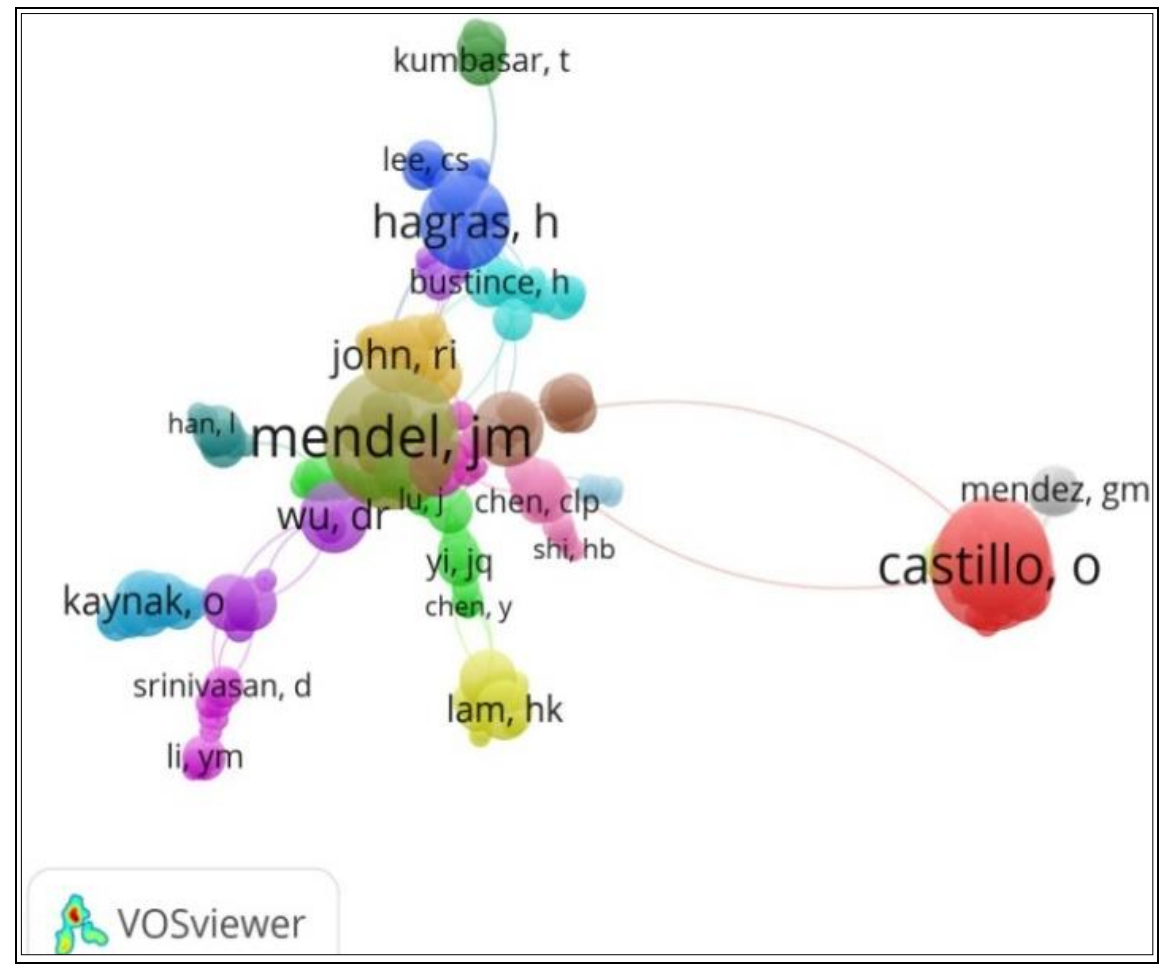

Fig. 5. Co-authorship structure of the field of T2 FSs.

\section{DisCUSSIONS AND CONCLUSION}

In this study, we have characterized the field of T2 FSs which has developed within the parent discipline of FSs. T2 FSs is a relatively new field, having originated only about 43 years ago in the USA (in 1975). The top 20 highly cited papers span about 14 years, from 1999 to 2012 indicating the importance of this period for the discipline. Twelve papers in this set of 20 are (co-) authored by Mendel. He has both the highest number of papers and by far the highest citations in the field. The authors with more than $10 \mathrm{TP}$, Mendel has the second highest citations per paper $(\sim 142.16)$, the highest being $\sim 157.72$ cites per paper obtained by John.

Among the top countries with researchers doing research on T2 FSs, we find China, followed by Iran, USA, and Taiwan. Papers published by the researchers in the USA have the highest total citations. Citations of the publications by Chinese researchers in the most recent 
period were the highest. Although researchers in China have produced the highest number of publications, there are only two Chinese institutions contributing to the top 20 list at ranks $11^{\text {th }}$ and $16^{\text {th }}$ with a total of $3.18 \%$ share. This implies that T2 FS research in China is distributed across a number of institutions. Taiwan has four institutions contributing to a total share of $6.06 \%$. There are three institutions from Iran which contributes of $6.28 \%$. Two institutions are from Mexico with \% share of $7.07 \%$.

The field appears to have a dual structure with a small well defined core of papers published in a few prominent and specialized journals, and a dispersed periphery of papers linked to applications which are spread out over a large variety of journals. There is a large potential for growth in application areas.

While WoS has a good coverage of journals, it may not cover all journals or proceedings of conferences - particularly the latter, which are considered to be an important contribution in Computer Science. Consequently, any paper published in a journal or proceedings not indexed by WoS were overlooked, even if important, in this study. Therefore, a very good future scope of this scientometric study would be to consider other indexing platforms such as Google scholar and Scopus for a thorough comparison with the WoS.

\section{REFERENCES}

[1] L. A. Zadeh, "Fuzzy sets," Information and Control, vol. 8, no. 3, pp. 338-353, Jun. 1965.

[2] E. Jimenez-Contreras and A. G. Lopez-Herrera, "Visualization and evolution of the scientific structure of fuzzy sets research in Spain," Information Research: An International Electronic Journal, vol. 14, no. 4, pp. 1-23, Dec. 2009.

[3] M. J. Cobo, A. G. López-Herrera, E. Herrera-Viedma, and F. Herrera, "An approach for detecting, quantifying, and visualizing the evolution of a research field: A practical application to the fuzzy sets theory field," Journal of Informetrics, vol. 5, no. 1, pp. 146166, Jan. 2011.

[4] J. M. Merigó, A. M. Gil-Lafuente, and R. R. Yager, "An overview of fuzzy research with bibliometric indicators," Applied Soft Computing, vol. 27, pp. 420-433, Feb. 2015.

[5] N. J. Van Eck and L. Waltman, "Bibliometric mapping of the computational intelligence field," International Journal of Uncertainty, Fuzziness and Knowledge-Based Systems, vol. 15 , no. 05 , pp. 625-645, Oct. 2007. 
[6] N. Van Eck, L. Waltman, J. Den Berg, and U. Kaymak, "Visualizing the computational intelligence field," IEEE Computational Intelligence Magazine, vol. 1, no. 4, pp. 6-10, Nov. 2006.

[7] V. K. Singh, S. K. Banshal, K. Singhal, and A. Uddin, "Scientometric mapping of research on 'Big Data,"' Scientometrics, vol. 105, no. 2, pp. 727-741, Sep. 2015.

[8] D. Yu, D.-F. Li, J. M. Merigó, and L. Fang, "Mapping development of linguistic decision making studies," Journal of Intelligent \& Fuzzy Systems, vol. 30, no. 5, pp. 2727-2736, Apr. 2016.

[9] D. Yu and S. Shi, "Researching the development of Atanassov intuitionistic fuzzy set: Using a citation network analysis," Applied Soft Computing, vol. 32, pp. 189-198, Jul. 2015.

[10] F. Blanco-Mesa, J. M. Merigó, and A. M. Gil-Lafuente, "Fuzzy decision making: A bibliometric-based review," Journal of Intelligent \& Fuzzy Systems, vol. 32, no. 3, pp. 2033-2050, Feb. 2017.

[11] M. J. Cobo, M. A. Martínez, M. Gutiérrez-Salcedo, H. Fujita, and E. Herrera-Viedma, "25 years at Knowledge-Based Systems: A bibliometric analysis," Knowledge-Based Systems, vol. 80, pp. 3-13, May 2015.

[12] A. K. Shukla, M. Janmaijaya, A. Abraham, and P. K. Muhuri, "Engineering applications of artificial intelligence: A bibliometric analysis of 30 years (1988-2018)." Engineering Applications of Artificial Intelligence, vol. 85, pp. 517-532, Oct. 2019.

[13] J. M. Merigó, W. Pedrycz, R. Weber, and C. de la Sotta, "Fifty years of Information Sciences: A bibliometric overview," Information Sciences, vol. 432, pp. 245-268, Mar. 2018.

[14] P. K. Muhuri, Z. Ashraf, and Q. M. D. Lohani, "Multi-objective reliability-redundancy allocation problem with interval Type-2 fuzzy uncertainty," IEEE Transactions on Fuzzy Systems, vol. 26, no. 3, pp. 1339-1355, Jun. 2017.

[15] R. John, "Type 2 fuzzy sets: An appraisal of theory and applications," International Journal of Uncertainty, Fuzziness and Knowledge-Based Systems, vol. 06, no. 06, pp. 563-576, Dec. 1998.

[16] J. M. Mendel, "On KM algorithms for solving Type-2 fuzzy set problems," IEEE Transactions on Fuzzy Systems, vol. 21, no. 3, pp. 426-446, Jun. 2013.

[17] J. M. Mendel and R. I. B. John, "Type-2 fuzzy sets made simple," IEEE Transactions on Fuzzy Systems, vol. 10, no. 2, pp. 117-127, Apr. 2002.

[18] R. John and S. Coupland, "Type-2 fuzzy logic: challenges and misconceptions [Discussion Forum]," IEEE Computational Intelligence Magazine, vol. 7, no. 3, pp. 4852, Aug. 2012.

[19] J. M. Mendel, R. I. John, and F. Liu, "Interval Type-2 fuzzy logic systems made simple," IEEE Transactions on Fuzzy Systems, vol. 14, no. 6, pp. 808-821, Dec. 2006.

[20] H. Hagras and C. Wagner, "Towards the wide spread use of Type-2 fuzzy logic systems in real world applications," IEEE Computational Intelligence Magazine, vol. 7, no. 3, pp. 14-24, Aug. 2012.

[21] H. Hagras, D. Alghazzawi, and G. Aldabbagh, "Employing Type-2 fuzzy logic systems in the efforts to realize ambient intelligent environments [Application Notes]," IEEE Computational Intelligence Magazine, vol. 10, no. 1, pp. 44-51, Feb. 2015.

[22] N. N. Karnik and J. M. Mendel, "Introduction to Type-2 fuzzy logic systems," in Fuzzy Systems Proceedings, vol. 2, pp. 915-920, May 1998.

[23] J. M. Mendel, "Explaining the performance potential of rule-based fuzzy systems as a greater sculpting of the state space," IEEE Transactions on Fuzzy Systems, vol. 26, no. 4, pp. 2362-2373, Aug. 2018. 
[24] L. A. Zadeh, "The concept of a linguistic variable and its application to approximate reasoning-I," Information Sciences, vol. 8, no. 3, pp. 199-249, Jan. 1975.

[25] J. M. Mendel, "Uncertainty, fuzzy logic, and signal processing," Signal Processing, vol. 80, no. 6, pp. 913-933, Jun. 2000.

[26] F. Liu, "An efficient centroid type-reduction strategy for general type-2 fuzzy logic system," Information Sciences, vol. 178, no. 9, pp. 2224-2236, May 2008.

[27] Q. Liang and J. M. Mendel, "Interval type-2 fuzzy logic systems: Theory and design," IEEE Transactions on Fuzzy Systems, vol. 8, no. 5, pp. 535-550, Oct. 2000.

[28] N. N. Karnik, J. M. Mendel, and Q. Liang, "Type-2 fuzzy logic systems," IEEE Transactions on Fuzzy Systems, vol. 7, no. 6, pp. 643-658, Dec. 1999.

[29] P. K. Muhuri, A. K. Shukla, and A. Abraham, "Industry 4.0: A bibliometric analysis and detailed overview," Engineering applications of artificial intelligence, vol. 78, pp. 218235, Feb. 2019.

[30] N. N. Karnik and J. M. Mendel, "Centroid of a type-2 fuzzy set," Information Sciences, vol. 132, no. 1-4, pp. 195-220, Feb. 2001.

[31] H. A. Hagras, "A hierarchical type-2 fuzzy logic control architecture for autonomous mobile robots," IEEE Transactions on Fuzzy Systems, vol. 12, no. 4, pp. 524-539, Aug. 2004.

[32] J. M. Mendel, "Type-2 fuzzy sets and systems: An overview [corrected reprint]," IEEE Computational Intelligence Magazine, vol. 2, no. 2, pp. 20-29, May 2007.

[33] N. N. Karnik and J. M. Mendel, "Operations on type-2 fuzzy sets," Fuzzy Sets and Systems, vol. 122, no. 2, pp. 327-348, Sep. 2001.

[34] J. M. Mendel, "Advances in type-2 fuzzy sets and systems," Information Sciences, vol. 177, no. 1, pp. 84-110, Jan. 2007.

[35] H. Wu and J. M. Mendel, "Uncertainty bounds and their use in the design of interval type-2 fuzzy logic systems," IEEE Transactions on Fuzzy Systems, vol. 10, no. 5, pp. 622-639, Oct. 2002.

[36] H. Hagras, "Type-2 FLCs: A new generation of fuzzy controllers," IEEE Computational Intelligence Magazine, vol. 2, no. 1, pp. 30-43, Feb. 2007.

[37] Q. Liang and J. M. Mendel, "Equalization of nonlinear time-varying channels using type2 fuzzy adaptive filters," IEEE Transactions on Fuzzy Systems, vol. 8, no. 5, pp. 551563, Oct. 2000.

[38] Dongrui Wu and J. M. Mendel, "Enhanced Karnik-Mendel algorithms," IEEE Transactions on Fuzzy Systems, vol. 17, no. 4, pp. 923-934, Aug. 2009.

[39] C. Hwang and F. C.-H. Rhee, "Uncertain fuzzy clustering: Interval Type-2 fuzzy approach to C-Means," IEEE Transactions on Fuzzy Systems, vol. 15, no. 1, pp. 107120, Feb. 2007.

[40] R. Martínez, O. Castillo, and L. T. Aguilar, "Optimization of interval type-2 fuzzy logic controllers for a perturbed autonomous wheeled mobile robot using genetic algorithms," Information Sciences, vol. 179, no. 13, pp. 2158-2174, Jun. 2009.

[41] J. M. Mendel, "Computing derivatives in interval type-2 fuzzy logic systems," IEEE Transactions on Fuzzy Systems, vol. 12, no. 1, pp. 84-98, Feb. 2004.

[42] S.-M. Chen and L.-W. Lee, "Fuzzy multiple attributes group decision-making based on the interval type-2 TOPSIS method," Expert Systems with Applications, vol. 37, no. 4, pp. 2790-2798, Apr. 2010.

[43] N. N. Karnik and J. M. Mendel, "Applications of type-2 fuzzy logic systems to forecasting of time-series," Information Sciences, vol. 120, no. 1-4, pp. 89-111, Nov. 1999. 
[44] P. Melin and O. Castillo, "A review on type-2 fuzzy logic applications in clustering, classification and pattern recognition," Applied Soft Computing, vol. 21, pp. 568-577, Aug. 2014.

[45] O. Castillo and P. Melin, "A review on interval type-2 fuzzy logic applications in intelligent control," Information Sciences, vol. 279, pp. 615-631, Sep. 2014.

[46] P. Melin and O. Castillo, "A review on the applications of type-2 fuzzy logic in classification and pattern recognition," Expert Systems with Applications, vol. 40, no. 13, pp. 5413-5423, Oct. 2013.

[47] O. Castillo and P. Melin, "A review on the design and optimization of interval type-2 fuzzy controllers," Applied Soft Computing, vol. 12, no. 4, pp. 1267-1278, Apr. 2012.

[48] D. Yu, Z. Xu, Y. Kao, and C.-T. Lin, "The structure and citation landscape of IEEE Transactions on Fuzzy Systems (1994-2015)," IEEE Transactions on Fuzzy Systems, vol. 26, no. 2, pp. 430-442, Apr. 2018.

[49] P. K. Muhuri, A. K. Shukla, M. Janmaijaya, and A. Basu, "Applied Soft Computing: A bibliometric analysis of the publications and citations during (2004-2016)," Applied Soft Computing, vol. 69, pp. 381-392, Aug. 2018.

[50] F. J. Martínez-López, J. M. Merigó, L. Valenzuela-Fernández, and C. Nicolás, "Fifty years of the European Journal of Marketing: a bibliometric analysis," European Journal of Marketing, vol. 52, no. 1/2, pp. 439-468, Feb. 2018.

[51] A. K. Shukla, R. Sharma, and P. K. Muhuri, "A review of the scopes and challenges of the modern real-time operating systems," International Journal of Embedded and RealTime Communication Systems, vol. 9, no. 1, pp. 66-82, Jan. 2018.

[52] M. Janmaijaya, A. Shukla, A. Abraham, and P. Muhuri, "A scientometric study of neurocomputing publications (1992-2018): An aerial overview of intrinsic structure," Publications, vol. 6, no. 3, pp. 1-32, Jul. 2018.

[53] J. M. Mendel, Uncertain rule-based fuzzy systems - Introduction and new directions, 2nd ed. Springer International Publish, 2017.

[54] D. Wu and J. M. Mendel, "Similarity measures for closed general type-2 fuzzy sets: overview, comparisons, and a geometric approach," IEEE Transactions on Fuzzy Systems, vol. 27, no. 3, pp. 515-526, Mar. 2019.

[55] https://jmmprof.wixsite.com/jmmprof. [Accessed: 09-Autumn-2018].

[56] J. M. Mendel, "Computing with words and its relationships with fuzzistics," Information Sciences, vol. 177, no. 4, pp. 988-1006, Feb. 2007.

[57] C. Wagner and H. Hagras, "Toward general type-2 fuzzy logic systems based on zSlices," IEEE Transactions on Fuzzy Systems, vol. 18, no. 4, pp. 637-660, Aug. 2010.

[58] A. K. Shukla and P. K. Muhuri, "General type-2 fuzzy decision making and its application to travel time selection," Journal of Intelligent \& Fuzzy Systems, vol. 36, no. 6, pp. 5227-5244, Jun. 2019.

[59] D. Wu and J. M. Mendel, "Uncertainty measures for interval type-2 fuzzy sets," Information Sciences, vol. 177, no. 23, pp. 5378-5393, Dec. 2007.

[60] J. R. Castro, O. Castillo, P. Melin, and A. Rodríguez-Díaz, "A hybrid learning algorithm for a class of interval type-2 fuzzy neural networks," Information Sciences, vol. 179, no. 13, pp. 2175-2193, Jun. 2009.

[61] D. Wu and J. M. Mendel, "A comparative study of ranking methods, similarity measures and uncertainty measures for interval type-2 fuzzy sets," Information Sciences, vol. 179, no. 8, pp. 1169-1192, Mar. 2009.

[62] J. M. Mendel, F. Liu, and D. Zhai, “ $\alpha$-plane representation for type-2 fuzzy sets: theory and applications," IEEE Transactions on Fuzzy Systems, vol. 17, no. 5, pp. 1189-1207, Oct. 2009. 
[63] R. Sepúlveda, O. Castillo, P. Melin, A. Rodríguez-Díaz, and O. Montiel, "Experimental study of intelligent controllers under uncertainty using type-1 and type-2 fuzzy logic," Information Sciences, vol. 177, no. 10, pp. 2023-2048, May 2007.

[64] C.-F. Juang and Y.-W. Tsao, "A self-evolving interval type-2 fuzzy neural network with online structure and parameter learning," IEEE Transactions on Fuzzy Systems, vol. 16, no. 6, pp. 1411-1424, Dec. 2008.

[65] D. Wu and J. M. Mendel, "Aggregation using the linguistic weighted average and interval Type-2 fuzzy sets," IEEE Transactions on Fuzzy Systems, vol. 15, no. 6, pp. 1145-1161, Dec. 2007.

[66] H. Li, C. Wu, P. Shi, and Y. Gao, "Control of nonlinear networked systems with packet dropouts: Interval type-2 fuzzy model-based approach," IEEE Transactions on Cybernetics, vol. 45, no. 11, pp. 2378-2389, Nov. 2015.

[67] F. Liu and J. M. Mendel, "Encoding words into interval type-2 fuzzy sets using an interval approach," IEEE Transactions on Fuzzy Systems, vol. 16, no. 6, pp. 1503-1521, Dec. 2008.

[68] J. M. Mendel, N. N. Karnik, and Q. Liang, "Connection admission control in ATM networks using survey-based type-2 fuzzy logic systems," IEEE Transactions on Systems, Man and Cybernetics, Part C (Applications and Reviews), vol. 30, no. 3, pp. 329-339, Aug. 2000.

[69] R. John and S. Coupland, "Type-2 fuzzy logic: A historical view," IEEE Computational Intelligence Magazine, vol. 2, no. 1, pp. 57-62, Feb. 2007.

[70] D. Wu and W. Wan Tan, "Genetic learning and performance evaluation of interval type2 fuzzy logic controllers," Engineering Applications of Artificial Intelligence, vol. 19, no. 8, pp. 829-841, Dec. 2006.

[71] O. Castillo, R. Martínez-Marroquín, P. Melin, F. Valdez, and J. Soria, "Comparative study of bio-inspired algorithms applied to the optimization of type-1 and type-2 fuzzy controllers for an autonomous mobile robot," Information Sciences, vol. 192, pp. 19-38, Jun. 2012.

[72] H. Bustince, E. Barrenechea, M. Pagola, and J. Fernandez, "Interval-valued fuzzy sets constructed from matrices: Application to edge detection," Fuzzy Sets and Systems, vol. 160, no. 13, pp. 1819-1840, Jul. 2009.

[73] S. Greenfield, F. Chiclana, S. Coupland, and R. John, "The collapsing method of defuzzification for discretised interval type-2 fuzzy sets," Information Sciences, vol. 179, no. 13, pp. 2055-2069, Jun. 2009.

[74] C.-S. Lee, M.-H. Wang, and H. Hagras, "A type-2 fuzzy ontology and its application to personal diabetic diet recommendation," IEEE Transactions on Fuzzy Systems, vol. 18, no. 2, pp. 374-395, Apr. 2010.

[75] D. Wu and J. M. Mendel, "A vector similarity measure for linguistic approximation: Interval type-2 and type-1 fuzzy sets," Information Sciences, vol. 178, no. 2, pp. 381402, Jan. 2008.

[76] A. K. Shukla and P. K. Muhuri, "Big-data clustering with interval type-2 fuzzy uncertainty modeling in gene expression datasets," Engineering Applications of Artificial Intelligence, vol. 77, pp. 268-282, Jan. 2019.

[77] H. Bustince et al., "A historical account of types of fuzzy sets and their relationships," IEEE Transactions on Fuzzy Systems, vol. 24, no. 1, pp. 179-194, Feb. 2016.

[78] H. B. Sola, J. Fernandez, H. Hagras, F. Herrera, M. Pagola, and E. Barrenechea, "Interval type-2 fuzzy sets are generalization of interval-valued fuzzy sets: Toward a wider view on their relationship," IEEE Transactions on Fuzzy Systems, vol. 23, no. 5, pp. 1876-1882, Oct. 2015. 
[79] J. M. Mendel, "Type-2 fuzzy sets, A tribal parody [Discussion Forum]," IEEE Computational Intelligence Magazine, vol. 5, no. 4, pp. 24-27, Nov. 2010.

[80] N. V. Eck and L. Waltman. "Software survey: VOSviewer, a computer program for bibliometric mapping." Scientometrics vol. 84, no. 2, pp. 523-538, Dec. 2009. 